\title{
Adecuación del medio bucal: protocolo de odontopediatría de la UNIGRANRIO, RJ - Brasil.
}

\section{Resumen}

La adecuación del medio bucal consiste en un conjunto de medidas que apuntan a la disminución de los niveles de microorganismos cariogénicos presentes en la cavidad bucal, proporcionando la paralización del proceso carioso. Las medidas se aplican después del diagnóstico y antes del tratamiento restaurador definitivo, siendo considerada una eta-
Thais Dias dos Santos, ${ }^{1}$ Ana Beatriz Amorim de Melo, ${ }^{1}$

Leila Maria Chevitarese, ${ }^{2}$ José Massao Miasato, ${ }^{2}$ Luciana Alves Herdy da Silva. ${ }^{2}$

Artigo da revisao

\section{Adequação do meio bucal: protocolo da odontopediatria da UNIGRANRIO, RJ - Brasil.}

\section{Resumo}

A adequação do meio bucal consiste em um conjunto de medidas que visam a diminuição dos níveis de microorganismos cariogênicos presentes na cavidade bucal, pa intermedia. El presente trabajo tiene como objetivo discutir la adecuación del medio bucal, sus etapas y presentar el protocolo utilizado en la Clínica de Odontopediatría de la UNIGRANRIO, RJ - Brasil.

Palabras clave: Adecuación del medio bucal, Caries dentaria, Prevención, Tratamiento odontológico, Odontología pediátrica, Odontología.

1. Universidade Unigranrio - Barra da Tijuca, Rio de Janeiro, Brasil.

2. Universidade Unigranrio - Duque de Caxias, Rio de Janeiro, Brasil.

proporcionando a paralisação do processo da doença cárie. As medidas são aplicadas após o diagnóstico e anteriormente ao tratamento restaurador definitivo, sendo considerada uma etapa intermediária. O presente trabalho tem por objetivo discutir 
a adequação do meio bucal, suas etapas e apresentar o protocolo utilizado na Clínica de Odontopediatria da UNIGRANRIO, Brasil.
Palavras-chave: Adequação do meio bucal, cárie dentária, prevenção, tratamento odontológico, odontopediatria, odontologia.

Article of revision

\section{Adequacy of the buccal environment: Pediatric dentistry protocol used at UNIGRANRIO, RJ - Brazil.}

\begin{abstract}
The adequacy of the oral environment consists of a set of measures aimed at reducing the levels of cariogenic microorganisms present in the oral cavity and arresting the caries disease process. These measurements are applied after the diagnosis but before the definitive restorative treatment; hence, being
\end{abstract}

\section{Introducción}

Se sabe que la caries dentaria es una enfermedad multifactorial, en la que cuando factores biológicos y no biológicos están en desequilibrio, pueden llevar a la aparición de lesiones de caries incipientes o cavitadas. ${ }^{1}$

La adecuación del medio bucal consiste en un conjunto de medidas que apuntan a la disminución de los niveles de microorganismos cariogénicos presentes en la cavidad bucal, buscando la paralización del proceso carioso. ${ }^{2}$ Estas medidas se aplican después del diagnóstico y anteriormente al tratamiento restaurador definitivo, siendo considerado una etapa intermedia con un tiempo de duración máximo de un mes..$^{2-5}$ Otra definición considered an intermediate step. The aim of this study was to discuss the adequacy of the oral environment, its stages and present the related protocol used in the Pediatric Dentistry Clinic of UNIGRANRIO, Brazil.

Key words: Adequate oral environment, Dental caries, Prevention, Dental treatment, Pediatric dentistry, Dentristry.

para esta modalidad de tratamiento es la aportada por Fraga et al., ${ }^{5}$ los cuales afirman que la adecuación del medio bucal es la oportunidad de eliminación de los factores que colaboran en el mantenimiento de un bajo $\mathrm{pH}$ en el medio bucal, y que están directamente ligados al proceso de desmineralización dentaria, el cual desfavorece la remineralización.

De este modo el presente trabajo pretende presentar el protocolo de adecuación del medio bucal utilizado en la Clínica de Odontopediatría de la UNIGRANRIO, RJ - Brasil, discutiéndolo a partir de sus etapas.

\section{Revisión de la literatura}

La caries dentaria ha sido reportada 
como una enfermedad oportunista, multifactorial, compuesta por biofilm (biopelícula) y $\mathrm{pH}$-dependiente, donde la dieta, la saliva y los determinantes sociocomportamentales tienen una fuerte influencia sobre la misma. ${ }^{6}$ La presencia de bacterias en el proceso carioso es bien entendida. Se sabe que su participación se da por medio de la organización y acumulación bacteriana en los tejidos mineralizados de la cavidad bucal, donde en presencia de azúcares fermentables y de tiempo, promueven la desmineralización del elemento dentario involucrado. ${ }^{5}$ El grado de escolaridad de los padres del paciente, su actitud y el acceso que tengan a la salud, pueden modificar la evolución de la enfermedad y por eso son considerados factores de confusión. ${ }^{7}$

Locker y Ford ${ }^{8}$ destacan a la renta familiar entre los aspectos socioeconómicos y comportamentales que influencian fuertementela severidad dela enfermedad, mostrando una mayor aparición de las lesiones de caries.

El índice de biofilm visible tiene como finalidad evidenciar las áreas donde el paciente presenta dificultad de limpieza, evaluar su destreza y psicomotricidad, además de posibilitar la reevaluación longitudinal del mantenimiento de la salud bucal..$^{9,10}$

Otro índice empleado para evidenciar la presencia de biofilm es el de sangrado al sondaje periodontal, que tiene como objetivo evidenciar áreas con biofilm espeso supragingival, los cuales pueden favorecer al desarrollo de la gingivitis. El índice de sangrado al sondaje periodontal permite conocer el patrón de remoción y control de biofilm, la evaluación de cambios comportamentales por parte del paciente, así como también reevaluar longitudinalmente el mantenimiento de la salud bucal. ${ }^{9,10}$ Las lesiones de caries se establecen en áreas en las que el biofilm se encuentra estancado, reafirmando que el surgimiento de lesiones cariosas es el resultado de la acumulación de biofilm dentario, por lo que es interesante que en cada consulta se evalúe la calidad y frecuencia de los hábitos de higiene oral. ${ }^{11}$ Aunque se hable sobre la multifactoriedad de la caries dentaria, ésta tiene una sola causa: el biofilm bacteriano. ${ }^{1}$

Una de las principales medidas preventivas y de control de la caries dentaria es la remoción mecánica del biofilm dentario a partir del uso del cepillo dental en conjunto con un dentífrico que preferiblemente contenga flúor e hilo dental. La desorganización del biofilm dentario es eficaz en el mantenimiento de la calidad de la salud bucal de toda la población, siendo ésta accesible financieramente y de fácil reproducción. ${ }^{6}$

En relación a la dieta, la recomendación es que el profesional conozca toda la información inherente a la alimentación del paciente, esencialmente las que exhiben algún potencial cariogénico. Es importante que el paciente reciba toda información sobre los alimentos que ofrecen riesgo de causar desequilibrio del medio bucal, influenciando el proceso de salud-enfermedad. Para que haya fidelidad en la obtención de los datos alimenticios, es esencial que el paciente haya comprendido tal importancia. ${ }^{12,13}$

Una manera de obtener los datos alimenticios del paciente, es a través del empleo de los diarios de dieta, ya que éstos permiten extraer la información alimenticia que se consume durante tres 
días consecutivos, excepto los fines de semana. De esta forma, es posible evaluar la consistencia, frecuencia y cantidad de ingestión de alimentos cariogénicos en la rutina del individuo. ${ }^{6}$ También es posible evaluar la adhesividad de los alimentos a través de los diarios de dieta. ${ }^{14}$

El empleo de flúor exhibe mínimos efectos entre los factores etiológicos de la caries, sin embargo, es considerado un factor determinante positivo en el proceso saludenfermedad de la caries, justamente por activar la precipitación de minerales, debido a su alta afinidad con los iones de calcio y fosfato, produciendo la reposición de los minerales perdidos durante el proceso de des/remineralización. ${ }^{15,16}$

La utilización tópica de flúor confiere cierta resistencia a la pérdida de minerales producto de la acción de los ácidos bacterianos en el biofilm dentario. La formación de fluorapatita, un mineral con menor solubilidad comparada con la hidroxiapatita, es importante para la reducción de la desmineralización. La aplicación tópica de flúor también es responsable de crear depósitos de iones de flúor (fluoruro de calcio) en las superficies dentales, el cual actuará lentamente en el proceso de des/remineralización. ${ }^{15,16}$ Debido a que el flúor tiene eficacia en el proceso dinámico de pérdida y reposición de minerales, es imprescindible que ocurra la remoción o disminución de los factores determinantes, en especial la desorganización del biofilm, puesto que no hay actuación directa del flúor en los factores etiológicos determinantes de la caries como enfermedad. ${ }^{15}$

La práctica educativa en odontología está fundamentada en propuestas que buscan ofrecer conocimientos al paciente, para de esta forma, posibilitar su participación efectiva en el control del proceso de salud-enfermedad. ${ }^{17}$ Por consiguiente, es importante que el profesional consiga despertar en el paciente la motivación que es necesaria para las transformaciones de hábitos y adopción de prácticas saludables. En cierto modo, el éxito del tratamiento está vinculado a la motivación que el profesional logre despertar en el paciente, ${ }^{17-19}$ por lo cual, es importante que los protocolos incluyan acciones educativas en salud, conduciendo el tratamiento de forma tal que ofrezca información y estimule cambios en el comportamiento del paciente con ayuda de la motivación.

La interrelación profesional-paciente en la práctica educativa en salud no debe ocurrir de forma vertical, a fin de eliminar cualquier actitud autoritaria por parte del Odontólogo. El profesional debe, en forma de educador, permitir que el paciente, en posición de educando, pueda manifestarse y trazar de forma conjunta soluciones terapéuticas. ${ }^{17}$ El Odontólogo, actuando como educador, tendrá la responsabilidad de observar y reflexionar sobre los factores que interfieren con la salud de su paciente. Los factores sociales tales como valores culturales, grado de escolaridad y estilo de vida, pueden interferir en el proceso de orientación del paciente. Estos factores pueden influir en el proceso de aprendizaje, facilitando o dificultando el mismo y, en cierta forma, induciendo el pensamiento del individuo en relación a la valoración de su salud. El profesional debe reconocer las necesidades individuales del paciente, que son completamente distintas durante las fases del desarrollo humano y que pueden ser propulsores de la motivación del paciente, estimulando de forma directa una toma de actitud. ${ }^{17,18}$ 
En la relación profesional-paciente, en odontopediatría es imprescindible que el Odontólogo esté preparado para abordar de forma personalizada a cada individuo, permitiendo la formación de un lazo de seguridad y confianza por parte del paciente y sus responsables. De esta forma, el profesional debe crear métodos para motivar, no sólo al paciente sino también a los familiares y cuidadores. ${ }^{17,18}$ Luego hay necesidad de que se realicen consultas con el objetivo de crear vínculos y acoger al paciente. ${ }^{20}$

La presencia de lesiones cavitadas de caries en la cavidad bucal han sido consideradas como un factor retentivo de biofilm dentario. Así, la restauración de las lesiones cavitadas con materiales provisionales, tiene el objetivo de disminuir la actividad de caries para que las medidas de prevención y control puedan ser aplicadas. ${ }^{4}$ En lo que se refiere a la restauración provisional masiva de las cavidades previamente cureteadas, el ionómero de vidrio se considera un material adecuado para este propósito, debido a la liberación de flúor, adhesión verdadera con el elemento dentario y su biocompatibilidad. $3,13,21$

En relación a la restauración de cavidades de caries que han sido parcialmente o totalmente cureteadas, se ha comprobado que su sellado promueve la interrupción de la obtención de nutrientes, lo que lleva a la inviabilidad de microorganismos, permitiendo así la paralización del proceso carioso. El éxito puede ser constatado por medio del reconocimiento del aspecto clínico de las lesiones profundas que se vuelven endurecidas y oscurecidas. ${ }^{21}$

En la clínica de Odontopediatría, al recibir al niño (paciente) y sus responsables,
Tabla 1 . Protocolo de Adecuación

del Medio Bucal utilizado en la clínica

de Odontopediatría de la

UNIGRANRIO, RJ - Brasil.

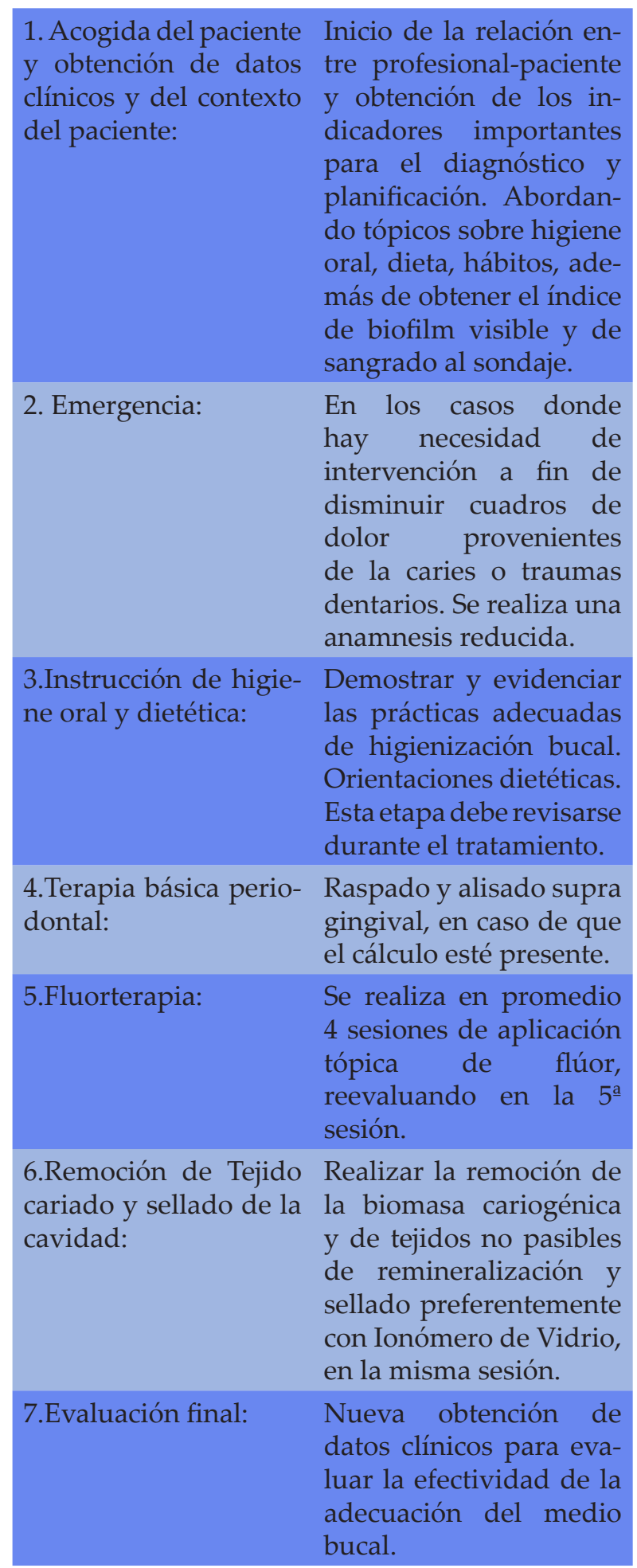


se realiza la anamnesis, que toma en consideración la queja principal, datos de historia anterior y actual, contexto social y conductual del paciente y su familia. A continuación, se realiza la evaluación clínica extra e intraoral, que incluyen entrevistas para saber sobre la dieta, la presencia y el control de biofilm y el examen clínico propiamente dicho después de la remoción del biofilm, estando las superficies dentarias limpias, secas y bien iluminadas.

Cuando nos enfrentamos a un paciente pediátrico que se presenta con un medio bucal desequilibrado debido a presencia de caries dentaria, la modalidad de tratamiento utilizada es la adecuación del medio bucal. La Tabla 1, muestra el protocolo y conjunto de medidas utilizadas en la clínica de odontopediatría de la Universidad del Gran Río (UNIGRANRIO), propuesta por el Profesor José de Souza Herdy. Es de notar que no todo paciente utilizará siempre todo el conjunto de medidas.

\section{Discusión}

El presente protocolo señala la acogida del paciente como una de las etapas en la atención odontológica. Gomes y Pinheiro ${ }^{22}$ comentan sobre los significados atribuidos a la palabra "acogida" en diferentes diccionarios (diccionario Aurélio de la lengua Portuguesa y diccionario Houaiss), entre los cuales están presentes: “atención, consideración, refugio, protección, confort físico, tener o recibir a alguien junto a usted" y los autores opinan que estas palabras no tienen conexión directa con el área de la salud, pero observaron que las mismas pueden ser atribuidas a los principios de la actuación en salud. ${ }^{21}$
En la atención odontopediátrica, el abordaje inicial debe ser realizado desde la sala de espera de forma atenta y afectuosa, buscando el establecimiento de un diálogo con el niño. ${ }^{22}$ Según Feldman y Miranda, $^{23}$ la construcción de una relación interpersonal involucra algunos principios $y$, uno de ellos puede ser destacado en la coyuntura de la relación entre el Odontólogo y el paciente, que apunta: "En el proceso de ayuda, el ayudante sintoniza, responde, personaliza y orienta al ayudado, y, en consecuencia, éste se involucra explorando donde está, comprende a dónde quiere llegar y actúa para llegar allí. "De forma convencida se considera la acogida, y no sólo ésta, sino también la obtención de datos del contexto del paciente, etapas indispensables en la atención odontológica, posibilitando así la iniciación y permanencia de métodos educativos en salud, a fin de esperar como resultado un paciente motivado y autónomo a cerca del mantenimiento de su propia salud bucal.

La obtención de los datos clínicos ocurre después del establecimiento de la relación entre el profesional y el paciente, siendo esta etapa muy importante para el correcto diagnóstico y para el control del proceso salud-enfermedad. Tuñas et al. ${ }^{24}$ también destacaron esta etapa como esencial, afirmando que sólo después de la acogida del paciente y la finalización de la obtención de los datos, será posible que el paciente pediátrico con la ayuda de sus familiares y siguiendo las orientaciones ofrecidas, se puedan auto-cuidar y disminuir sus índices de biofilm visible y sangrado gingival. Es importante resaltar que la acogida hace que el vínculo se establezca, creando lazos de confianza mutua. Esta relación ayuda en el rescate de la salud del paciente, ya que hay 
disposición por parte de quien habla - el Odontólogo, y por parte de quien escucha - el paciente pediátrico y sus cuidadores, en construir un proyecto terapéutico capaz de promover la autonomía en el control de su salud según lo discutido anteriormente. La participación de los cuidadores en el caso de los niños necesita ser resaltado, pues son ellos quienes al comprender el proceso salud-enfermedad en el niño, podrán ayudarlos en el control del equilibrio de su salud bucal y finalmente en su autonomía. La participación del cuidador será fundamental a lo largo de las sesiones que forman parte del plan de tratamiento de la adecuación del medio bucal.

Para los casos de pacientes que ingresan por emergencia, el examen debe realizarse de forma inmediata. ${ }^{25}$ En estos casos, donde el individuo se encuentra con dolor, no se debe perder el foco principal, que es el control del mismo. En estas circunstancias, se debe realizar una anamnesis reducida. Se resalta que el académico en Odontología necesita ser instruido para elaborar un plan de tratamiento priorizando los procedimientos, incluso durante la realización de la adecuación del medio bucal. En cuanto a la realización de los diferentes procedimientos en los casos de emergencia, no se debe renunciar a la anamnesis, sin embargo, es necesario saber conducirlos para atender el objetivo primario de la consulta, el cual, en este caso, es la eliminación del dolor del paciente, prescribiendo medicamentos adecuados en cada caso cuando sea necesario. ${ }^{25}$

Diferentes autores ${ }^{3,6,11,15}$ llaman la atención sobre la importancia de la desorganización de la comunidad bacteriana sobre la estructura dentaria a fin de paralizar el proceso de desmineralización de su superficie. La instrucción de higiene bucal engloba tres aspectos vinculados a ella: la remoción mecánica del biofilm dentario, la evaluación de la fuerza necesaria para la remoción del mismo y la adecuación de la frecuencia del cepillado dentario en la rutina diaria del paciente. Para una correcta remoción mecánica del biofilm dentario, resalta la importancia de capacitar al paciente, con la ayuda del Odontólogo, para que desarrolle su autonomía en la forma más adecuada para la práctica diaria de su higiene bucal, yendo al encuentro de lo que Cury y Tenuta $^{15}$ afirmaron, evidenciando que los mismos están aptos para remover el factor que desarrolla la enfermedad, que es la acumulación del biofilm. La mecánica de la desorganización del biofilm necesita ser enseñada y aprendida de modo que ella pueda alcanzar el objetivo que se propone. De ahí la importancia de incluir la instrucción de higiene bucal, teniendo en cuenta los tres aspectos ligados a ella, en las sesiones clínicas que forman parte del plan de tratamiento programado en la adecuación del medio, para que se pueda alcanzar la autonomía de los pacientes, sean ellos niños o adultos.

La investigación dietética se hace necesaria teniendo en cuenta el impacto de la alta ingestión de azúcares fermentables que se forman en el biofilm dentario. Se sabe que inmediatamente después del consumo de diversos tipos de alimentos que contienen azúcares, se producen variaciones del $\mathrm{pH}$ del biofilm. ${ }^{14}$ Esta variación del $\mathrm{pH}$ influye directamente en la formación de lesiones cariosas, ya que permite la disolución de minerales dentarios. Una maniobra que suele ser utilizada en Odontopediatría es la del consumo inteligente del azúcar, 
que busca el consumo de alimentos productores de azúcares en los momentos en que los elementos dentarios puedan ser higienizados. Preferiblemente, ese consumo debeser realizado después delas principales comidas diarias, evitando de esta forma que los períodos de desmineralización superen a los de remineralización. Por lo tanto, incluir la orientación del consumo inteligente del azúcar en las sesiones del plan de tratamiento ligado a la adecuación del medio bucal, se muestra como una maniobra importante para el ajuste compartido (Odontólogo y paciente/ cuidador) para el consumo de una dieta sana, contribuyendo al reequilibrio del medio bucal.

La remoción o disminución de los factores retentivos de biofilm está también presente dentro del elenco de procedimientos involucrados en las sesiones del protocolo de la adecuación bucal. El cálculo supragingival, restauraciones con excesos o fallas y las cavidades provenientes de procesos cariosos, son considerados factores retentivos, por justamente aumentar la acumulación local de biofilm dentario. ${ }^{26}$ Así, incluir la remoción de los mismos en las sesiones del plan de tratamiento relacionada con la adecuación del medio bucal forma parte del protocolo utilizado en la Clínica de Odontopediatría de UNIGRANRIO.

Los beneficios del flúor tópico en el control de la caries como enfermedad ya han sido destacados y se sabe que promueven el aumento de la deposición de minerales y a la desaceleración de la pérdida de estos mismos. Para que su efecto sea potencializado, se hace necesaria la creación de rutinas diarias para la realización correcta de la higiene bucal, el empleo de dentífricos fluorados y la aplicación del consumo inteligente del azúcar. En la presencia de lesiones activas de caries, ya sean incipientes o no, es necesaria la aplicación tópica profesional de flúor, siendo la elección del vehículo dependiente de la edad del niño. Incluimos, cuatro sesiones de flúor profesional y en la quinta, se reevalúa el éxito del tratamiento empleado.

\section{Conclusiones}

De esta forma se observa que es fundamental la obtención de datos que permitan un diagnóstico más preciso, posibilitando la oferta de procedimientos que pueden variar desde tratamientos no invasivos hasta la inclusión concomitante de tratamientos invasivos. Es esencial que el elenco de procedimientos distribuidos por sesiones en el protocolo de adecuación del medio bucal, apunten a la paralización de la enfermedad antes de que cualquier procedimiento restaurador definitivo sea realizado. El control de la caries como enfermedad es lo que se anhela cuando se utiliza el protocolo de adecuación del medio bucal en la clínica de Odontopediatría de UNIGRANRIO.

\section{Referencias bibliográficas}

1. Leites, Antonio Cesar Bortowiski Rosa; Pinto, Marcia Bueno; Sousa, Ezilmara Rolim de Sousa. Aspectos microbiológicos da cárie dental. Salusvita, Bauru. 2006; 25(2): 239- 252.

2. Oliveira, LMC; Neves, AA; Souza, IPR. Tratamento Restaurador Atraumático e Adequação do Meio Bucal. RBO. 1998; 55(2): 9-99.

3. Silva, Francisco Wanderley Garcia de Paula e; Queiroz, Alexandra Mussolino de; Freitas, Aldevina Campos de Assed, Sada. Utilização do ionômero de vidro em odontopediatria. Odontol. Clín.-Cient. (Online). 2011; 10(1): 13-17. 
4. Fraga CPT, Roulet PC, Guedes-Pinto AC, Exame Diagnóstico e Plano de Tratamento. In: Guedes-Pinto, A. C. Odontopediatria, 9 ed. Santos, 2016. Cap. 18. pag. 198-200.

5. Medeiros UV, Maia KD, Jorge RR. O desafio da prática educativa em odontologia. Rev. Bras. Odontol. 2010 jan./jun; 67(1): 49-55.

6. Oliveira LJE. Cárie dentária: um novo conceito. Rev R Dental Press Ortodon Ortop Facial. 2007 Dec; 12 (6): 119-130.

7. Maltz M, Cury J, Tenuta L, Groisman S. Cárie Dental: Conceitos e Terminologia. In: Maltz M, Cury J, Tenuta L, Groisman S. Cariologia, 1ae ed. São Paulo: Artes Médicas, 2016. Cap. 1 Pag. 11-16.

8. Locker D, Ford .1: Evaluittioti ol' itn area-based tTteasure as an indicator of itiequalitics in oral health, Cotntnunity Dent Oral Epidemiol 1994; 22: 80-5, (c) Munksgaard, 1994.

9. Salvi GE, Berglundh T, Lang NP. Avaliação dos pacientes In: Lang NP, Lindhe J. Tratado de Periodontia Clínica e Implantologia Oral, 6a ed. 2018. Cap. 29. Pag. 524.

10. Chiapinotto, FA; Vargas-Ferreira, F; Flávio Fernando Demarco, FF; Corrêa, FOB; Severo Masotti, AS. Avaliação da redução do índice de placa visível e do índice de sangramento gengival em uma prática de promoção de saúde bucal com crianças. Pesqui Odontol Bras 2002;16(2):169-174.

11. Peres KG, Bastos JR, Latorre MRDO. Severidade de cárie em crianças e relação com aspectos sociais e comportamentais. Rev Saúde Pública. 2000; 34(4): 402-8.

12. Bastos LF, Reis R, Medeiros UV, Harari SG. Diagnóstico da cárie dental: determinado por uma cavitação ou por uma análise multifatorial? UFES Rev. Odontol. 2000; 2(2): 42-46.

13. Lázaro, C. P.; Valença, A. M. G.; Chiappini,. C. C. J. Estudo preliminar do potencial ... escolar através do pH da saliva Rev. Nutr. 1999; 12(3): 273-287.

14. Cury JA, Tenuta LMA, Uso de Fluoreto em Odontologia Restauradora Fundamentado em Evidências. In: Baratieri, L. N., Monteiro Junior, S. Odontologia Restauradora Fundamentos e Possibilidades. 2 ed. São Paulo. Santos; 2017. Cap. 2.

15. Tenuta LMA, Cury J. Uso de fluoretos no controle da doença cárie. In: Maltz M, Tenuta LMA, Groisman S, Cury J. Cariologia: Conceitos básicos, diagnóstico e tratamento não restaurador. Cap.7. São Paulo : Artes Médicas, 2016.

16. Pontes FCC. Decisões Clínicas sobre Remoção do Tecido Cariado. In: Monnerat AF. TRA-Tratamento Restaurador Atraumático: Abordagem Clínica em Saúde Pública-Conceito, Técnica, Tratamento e Materiais. $1^{\text {a }}$ ed. Rio de janeiro. Elsevier Brasil: 2015. p. 71-85.

17. Ferreira S, Guedes-Pinto AC. Educação do paciente em Odontopediatria. In: A.Guedes-pinto, ed., Odontopediatria, 9ae ed. São Paulo: Santos, 2016 p.332.

18. Canalli CSE, Gonçalves SS, Chevitarese L, Silveira RG, Miassato JM A humanização na Odontologia: uma reflexão sobre a prática educativa. Rev. bras. odontol., Rio de Janeiro. 2011; 68(1): 44-8.

19. Pinto VG. Educação em saúde Bucal. In: Pinto VG. Saúde Bucal Coletiva. 4 ed. São Paulo. Santos; 2000. p. 311-312.

20. Ferreira CM. A transmissibilidade da Doença Cárie. RECS: R. Cent. Ci. Saúde, Fortaleza. 2001; 14(1): 51-54.

21. Gomes, M. C. P. A; Pinheiro, R. Reception and attachment: integral practices in health care administration in large urban centers. Interface - Comunic., Saúde, Educ., Interface - Comunic., Saúde, Educ. 2005; 9(17)::287-301.

22. Ferreira S, Guedes-Pinto AC. Manejo da criança no consultório. In: A. Guedes-Pinto, ed., Odontopediatria, 9ª ed. São Paulo: Santos, 2016.

23. Feldman C, Miranda MC. Construindo a relação de ajuda. $1^{\mathrm{a}}$ ed. Belo Horizonte: Editora Crescer. . 2002, p.261.

24. Tuñas IC, Maia KD, Passos M, Arkader RJ, Weyne S. Protocolo clínico para avaliação e controle do processo saúde-doença cárie. Rev. bras. odontol. 2015; 72(1-2): 76-86.

25. Rocha, RG; Tortamano, N; Adde, CA; Simone, JL; Perez, FEG. O controle da dor em odontologia através da terapêutica medicamentosa. Anais do $15^{\circ}$ Conclave Odontológico Internacional de Campinas. 2003; 104:1-30.

26. Silveira JLGC da, Oliveira V de, Padilha WWN. Avaliação da redução do índice de placa visível e do índice de sangramento gengival em uma prática de promoção de saúde bucal com crianças. Pesqui Odontol Bras. 2002;16(2):169-174.

Recibido: 23/11/18

Aceptado: 01/06/19

Correspondencia: Thais Dias, e-mail: diasthaissantos2@gmail.com 